Article

\title{
Numerical and Experimental Analysis of Flow Pattern, Pressure Drop and Collection Efficiency in a Cyclone with a Square Inlet and Different Dimensions of a Vortex Finder
}

\author{
Ryszard Wójtowicz $^{1, *(\mathbb{D})}$, Paweł Wolak ${ }^{2}$ (D) and Agnieszka Wójtowicz-Wróbel ${ }^{3}$ (D) \\ 1 Institute of Thermal and Process Engineering, Division of Industrial Equipment and Fluid Mechanics, \\ Cracow University of Technology, Al. Jana Pawła II 37, 31-864 Cracow, Poland \\ 2 Air Liquide Global E\&C Solutions Poland S.A., ul. Mogilska 41, 31-545 Cracow, Poland; \\ pawel.wolak@airliquide.com \\ 3 Department of Spatial Planning, Urban and Rural Design, Faculty of Architecture, \\ Cracow University of Technology, ul. Warszawska 24, 31-155 Cracow, Poland; awojtowicz@pk.edu.pl \\ * Correspondence: rwojtowi@pk.edu.pl; Tel.: +48-12-628-3288
}

check for updates

Citation: Wójtowicz, R.; Wolak, P.; Wójtowicz-Wróbel, A. Numerical and Experimental Analysis of Flow Pattern, Pressure Drop and Collection Efficiency in a Cyclone with a Square Inlet and Different Dimensions of a Vortex Finder. Energies 2021, 14, 111 . https://dx. doi.org/10.3390/en14010111

Received: 3 November 2020 Accepted: 23 December 2020 Published: 28 December 2020

Publisher's Note: MDPI stays neutral with regard to jurisdictional claims in published maps and institutional affiliations.

Copyright: (c) 2020 by the authors. Licensee MDPI, Basel, Switzerland. This article is an open access article distributed under the terms and conditions of the Creative Commons Attribution (CC BY) license (https: / / creativecommons.org/ licenses/by/4.0/).

\begin{abstract}
The paper presents results of numerical simulations and experimental investigations of a cyclone with a square inlet and different dimensions of a vortex finder. Investigations were conducted for five, different cyclone models. The main goal of the research was to determine the influence of cyclone vortex finder geometry (diameter, length) on key parameters for a cyclone operation, such as: gas flow pattern, gas velocity and pressure distribution, pressure drop and collection efficiency. The analysis of flow pattern inside the cyclone was carried out with the use of CFD (Computational Fluid Dynamics) simulations, verified using CTA (Constant Temperature Anemometry). Similarly, pressure distributions, pressure drop and collection efficiency for cyclones were determined numerically and with measurements. The study demonstrated that dimensions of the vortex finder have a significant effect on a cyclone performance. The numerical visualisations of flow showed some unfavorable and beneficial effects and phenomena that may occur in cyclones. Moreover, the smallest pressure drop (305 Pa) was predicted for the cyclone with a maximum diameter of the vortex finder $\left(D_{e}=0.105 \mathrm{~m}\right)$, the largest $(358 \mathrm{~Pa})$ when this diameter was the smallest $\left(D_{e}=0.075 \mathrm{~m}\right)$. The tests did not show any significant influence of the vortex finder length on the pressure drop in a cyclone. A different tendency was observed in the case of collection efficiency. The maximum value of this parameter $(89.5 \%)$ was predicted for the cyclone with the shortest vortex finder $(s=0.060 \mathrm{~m})$, minimum $(85.5 \%)$ when the vortex finder was the longest $(s=0.220 \mathrm{~m})$. In this case, however, tests did not show a significant impact of an outlet diameter on the collection efficiency. Results and conclusions presented in this paper can be practically used for design optimization of cyclone separators, and also to select their operating parameters.
\end{abstract}

Keywords: dust removal; cyclone separator; vortex finder; gas flow pattern; pressure drop; CFD simulations; CTA mesaurements; pressure drop

\section{Introduction}

The emission of dusts in waste gases occurs in many processes involving energy and heat production, both in large-scale, where energy production technologies are based on coal combustion [1,2] and when energy is produced in smaller-scale, e.g., from recovered heat during combustion in sludge incineration plants or municipal waste incineration plants [3,4]

Depending on the specifics of the production processes, their technology and scale, various devices can be used to remove dust pollution from the exhaust gases emitted to the environment. The most commonly used are: centrifugal dust collectors (cyclones, multicyclones), filters (cloth, ceramic), electrofilters and scrubbers.

Cyclones are very popular devices. Their most important advantages are: simple and compact design, no moving parts, simple and easy operation, low investment and 
operating costs and the ability to work at high temperatures and pressures in conditions of various gas humidity $[5,6]$.

Some significant research findings in the field of cyclone performance and their geometry optimization were presented in [7-10]. Investigations were focused on impact of a dust outlet geometry [7], cone-tip diameter [8] inlet height and width, vortex finder geometry or a total cyclone height $[9,10]$ on cyclone operation and its collection efficiency.

The results of tests of cyclone separators with tangential inlet are also presented in [11-20]. In [11-14] the Authors analysed an impact of cyclone length on its operating characteristics. The paper [11] presents test results and simulations of high-efficiency Stairmand cyclone [12] for its different total length. It was analyzed how an increasing the cyclone length influenced its collection efficiency and pressure drop.

In research [13] not only the cyclone length but also the diameter of a vortex finder was changed. The Authors, for three variants of cyclone design analyzed gas velocity and turbulence intensity distributions inside the cyclone body as well as the collection efficiency and the pressure drop. Investigations described in [14] were focused on determination of length of a cyclone with tangential inlet. On the basis of theoretical considerations and experimental results correlations for determination of an optimal length of a cyclone for its maximum efficiency were proposed. Research [15] was focused on simulations of the performance of a cyclone with various dust outlet geometry. Two cyclones had a cylindrical dust hopper, differing in diameter, the other three ones had an additional, different length down-comer tube, between the cone and the hopper. Results of simulations showed, that properly selected down-comer tube can improve cyclone performance. In [16], on the basis numerical simulations gas flow in various, cone-shaped vortex finders was optimized. An optimal model of collection efficiency for the cone-shaped vortex finder was chosen based on numerical experiments and measurements. In the paper [17] standard cyclone separator with tangential inlet and pipe vortex finders was investigated.The Authors suggest that selection of the cyclone exit pipe should be taken into account to maximize the efficiency of its collection efficiency and reduce pressure drop.

A detailed, numerical and experimental analysis of the gas flow hydrodynamics in the cyclone barrel was described in [18]. Research was focused on determination of gas velocity components (tangential, axial) in the zone, directly under a vortex finder. The Authors provided qualitative and quantitative description of turbulent flow in the barrel and presented interesting visualizations in the form of vector and contour maps for separation zone between forced and free vortex.

Research on gas outlet design in the cyclone with tangential inlet was presented also in $[19,20]$. In [19] for a standard geometry cyclone, so-called cross-shaped vortex finder with the arrangement of internal baffles was used. This design reduced the pressure drop in the cyclone and slightly increased its collection efficiency. Authors of paper [20] investigated cyclones with a tangential inlet and three variants of exhaust: circular and two square. The construction of the cyclone body is also innovative because it has a square cross section. The Authors based on simulations and measurements analyzed gas flow, turbulence parameters and particle trajectories inside cyclones.

The original-other than standard-design of cyclone separators is presented in [21-31], including modified standard cyclone with tangential inlet by addition a vortex stabilizer in the form of a vertical rod, located in the axis of the cyclone [21], cyclones with helical-roof inlet $[22,23]$ particle-sorting cyclones with additional particle sorting classifier before a gas inlet [24,25], divergent cyclones [26], cyclones with an axial inlet [27-29], axial flow cyclones [30] and small scale cyclones applied for nano-particle removal [31].

As the literature analysis showed, the design of the cyclone (including vortex finder geometry) primarily determines its performance and effectiveness of operation.

The present paper presents the first part of the research, focused on a basic information on flow pattern, vortices location and scale, flow velocity, pressure distribution, pressure drop and collection efficiency. It also described similarities and differences of 
these quantities for vortex finder variants. Therefore, this research was conducted in a relatively wide range and numerical models were verified with measurements.

The future research will analyze other operating parameters for cyclones, especially those characterizing two-phase flow: particle tracks, particle deposit in a barrel and dust hopper, fractional collection efficiency, maximum, minimum and cut-off diameters for collected particles, calculated on the basis of measurements as well as numerical simulations for a wider range of gas inlet velocities $\left(u_{i n}=10 \div 20 \mathrm{~m} / \mathrm{s}\right)$. This will allow to optimize (multiparameter analysis) the construction of cyclones and to select the best design in terms of pressure drop and collection efficiency.

\section{Experimental Setup}

Figure 1 presents a view, geometry and overall dimensions of basic model of tested cyclone. The diameter of its barrel was $D=0.192 \mathrm{~m}$ and the total height of the cyclone $H=0.745 \mathrm{~m}$. The inlet was square cross-sectional, with dimensions $a=b=0.042 \mathrm{~m}$ and total length $c=0.2 \mathrm{~m}$. The height of the barrel $h_{1}=0.242 \mathrm{~m}$. The cone tip diameter was chosen to be $B=0.045 \mathrm{~m}$. The diameter and length of the vortex finder for all examined variants are listed in Table 1, while Figure 2 shows geometry of each of them. In Figure $1 \mathrm{~b}$ are also marked specific, horizontal, cross-section planes $z_{1}-z_{4}$, located as follows: $z_{1}$-inlet cross-section plane, $z_{2}$-cross-section plane at the tip of the vortex finder, $z_{3}$-cross-section plane in the zone of connection of barrel and cone, $z_{4}$-cross-section plane in a half-height of cone. For these characteristic planes, flow parameters will be analyzed first of all.

a)

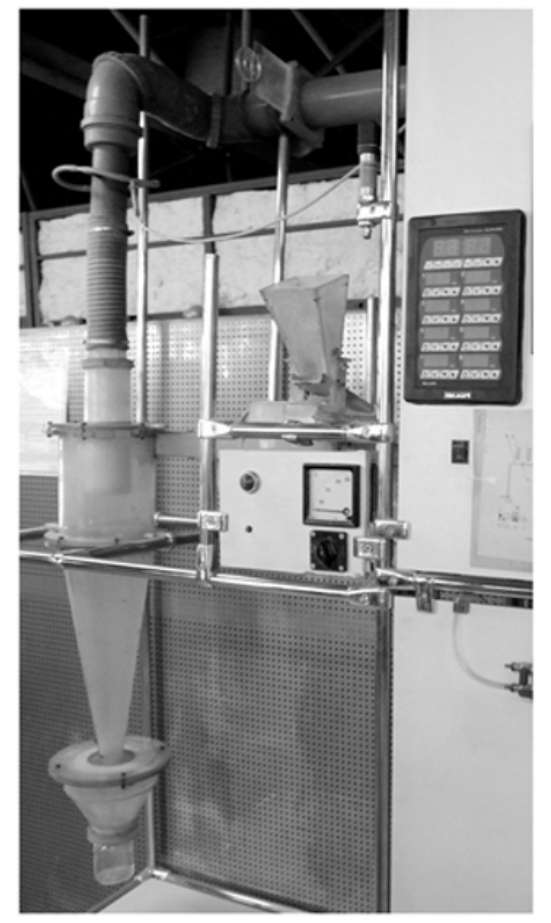

b)

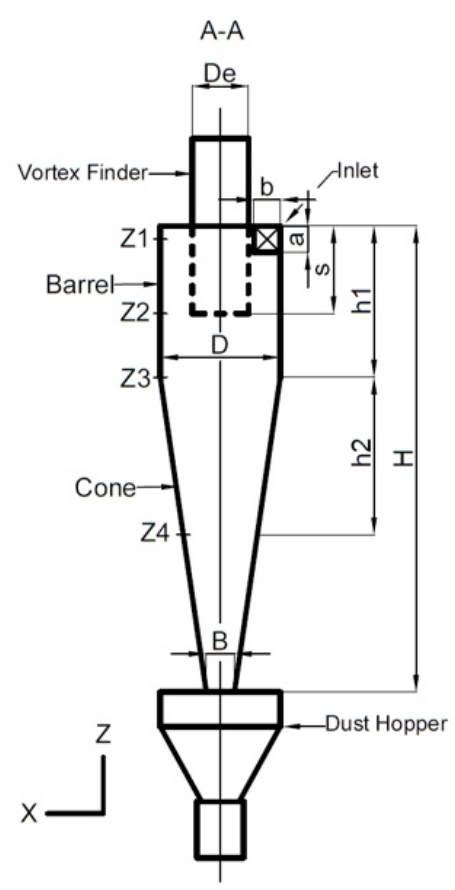

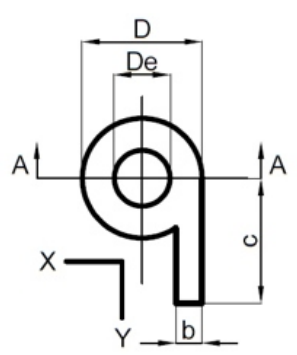

Figure 1. The cyclone examined (basic model) (a) general view, (b) geometry and overall dimensions. 
Table 1. Dimensions of the vortex finder.

\begin{tabular}{cccc}
\hline Vortex Finder & Model & $\mathbf{s}[\mathbf{m}]$ & $\mathbf{D}_{\boldsymbol{e}}[\mathbf{m}]$ \\
\hline basic model & I & 0.140 & 0.090 \\
maximum length & II & 0.220 & 0.090 \\
minimum length & III & 0.060 & 0.090 \\
maximum diameter & IV & 0.140 & 0.105 \\
minimum diameter & V & 0.140 & 0.075 \\
\hline
\end{tabular}

a)

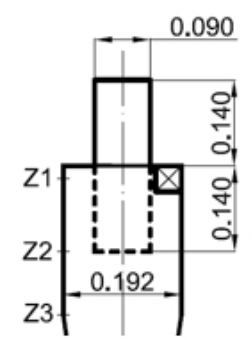

Cyclone I

basic model

c)

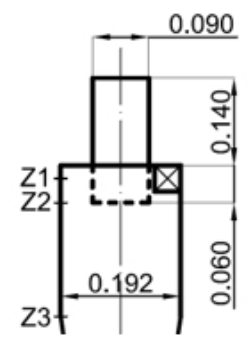

Cyclone III minimum length b)

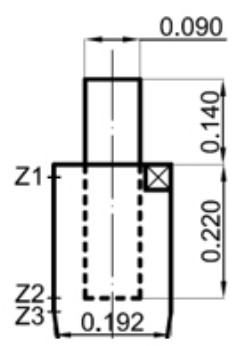

Cyclone II maximum length

d)

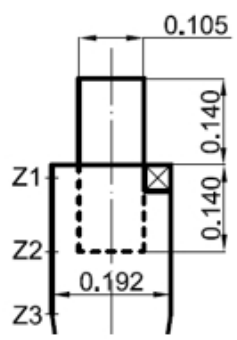

Cyclone IV maximum diameter

e)

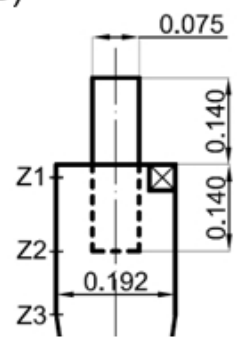

Cyclone V

minimum diameter

Figure 2. The vortex finder geometry: (a) cyclone I (basic model), (b) cyclone II (maximum length), (c) cyclone III (minimum length), (d) cyclone IV (maximum diameter), (e) cyclone IV (minimum diameter).

The gas flowing through the cyclone was air $\left(\rho_{c}=1.225 \mathrm{~kg} / \mathrm{m}^{3}, \mu_{c}=1.7894 \times 10^{-5} \mathrm{~Pa} \cdot \mathrm{s}\right)$, with inlet velocity $u_{\text {in }}=15 \mathrm{~m} / \mathrm{s}$. The solid particles (talcum powder) have density of $\rho_{s}=2700 \mathrm{~kg} / \mathrm{m}^{3}$. Their size distribution can be approximated by the Rosin-Rammler theoretical distribution, whose main parameters are listed in Table 2. Dispersed phase volume fraction was relatively low, lower than $5 \%$. 
Table 2. Main statistical parameters of particles population.

\begin{tabular}{cc}
\hline Quantity & Value \\
\hline Minimum diameter $d_{\text {min }}$ & $2 \mu \mathrm{m}$ \\
Maximum diameter $d_{\text {mmax }}$ & $100 \mu \mathrm{m}$ \\
Mean diameter $d_{p m n}$ & $24.7 \mu \mathrm{m}$ \\
Sauter mean diameter $d_{32}$ & $51.5 \mu \mathrm{m}$ \\
Standard deviation $\sigma$ & $17.3 \mu \mathrm{m}$ \\
Spread parameter $\beta$ & 2.537 \\
Total number of particles used for simulations $n$ & $5.321 \times 10^{6}$ \\
\hline
\end{tabular}

\section{Methodology of Numerical Simulations}

The helpful tools that can be successfully used during design and optimizing the operation of device and equipment, applied in energy production processes [31-33], chemical engineering [34-36], process engineering [37-39] and environmental protection processes [40-42] are computer simulation packages, based on specially created codes of Computational Fluid Dynamics (CFD) [43,44]. Their advantages such as the universality of application, ability to quickly modify size and geometry of designed device and also broad possibility of simulations single and multiphase flows, make them useful for analysis, re-scaling and design optimization of dust separators, including cyclones.

The analysis of two-phase flow in cyclones was performed based on results of numerical modelling, using as a pre-processor mesh generators: Gambit 2.4 [45] and Ansys Meshing [46]. As a solver Ansys Fluent $14.0[47,48]$ was used.

Numeric grids consisted of about $3 \times 10^{5}$ tetrahedral cells. The grid structure is shown in Figure 3.

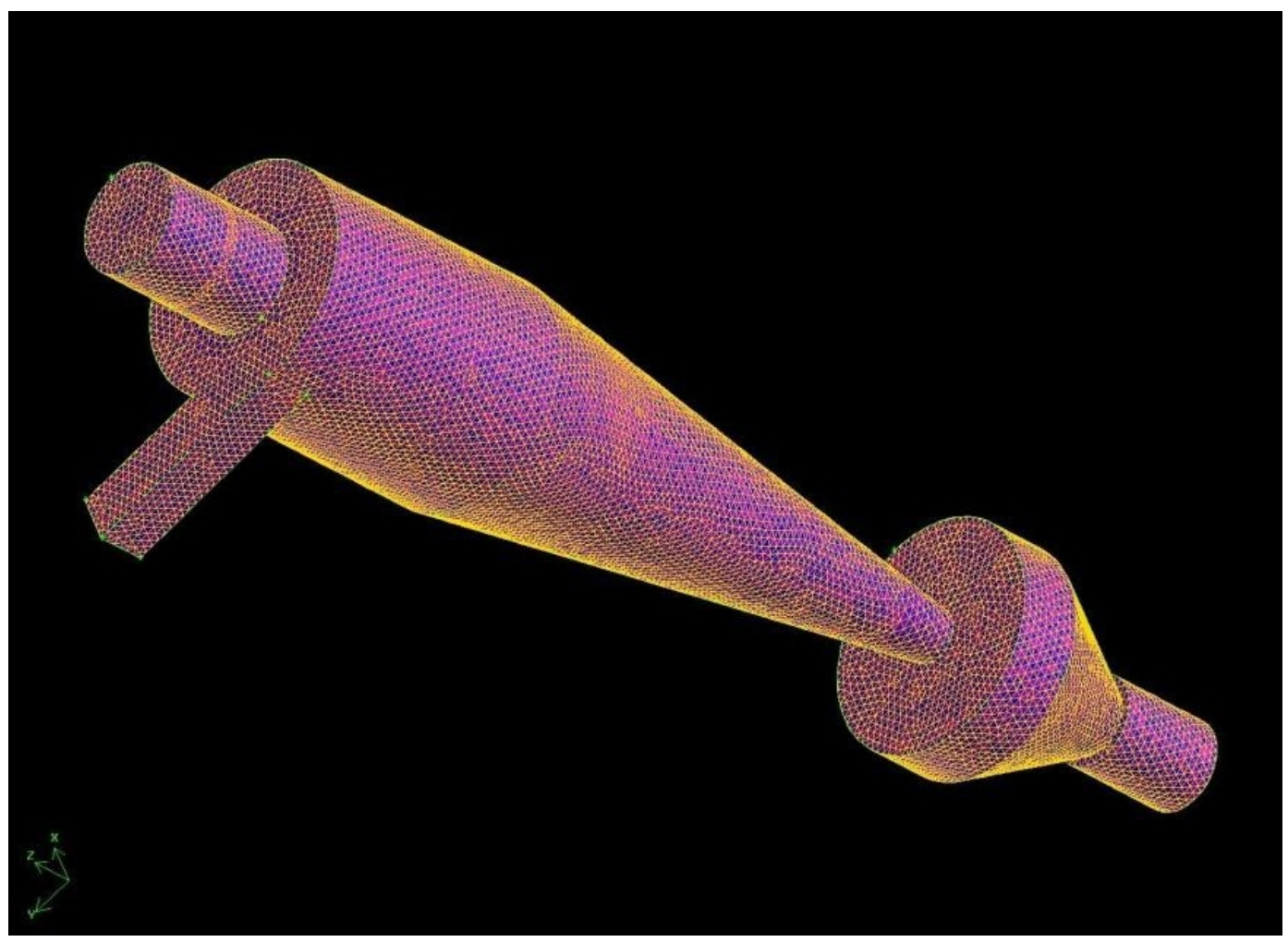

Figure 3. The grid generated for the examined cyclone.

The quality of grids was checked using, normalized EquiAngle Skew $\left(\mathrm{Q}_{E A S}\right)$ and EquiSize Skew (Q $\left.\mathrm{Q}_{E S S}\right)$ criteria. Both criteria have the same metrics (skewness) and reference scale. 
The metric of skewness for EquiAngle Skew $\left(\mathrm{Q}_{E A S}\right)$ criterion was determined from the formula:

$$
Q_{E A S}=\max \left\{\frac{\theta_{\max }-\theta_{e q}}{180-\theta_{e q}} ; \frac{\theta_{e q}-\theta_{\min }}{\theta_{e q}}\right\}
$$

where: $\theta_{\max }$ and $\theta_{\min }$ are maximum and minimum values of angles between edges of cell, $\theta_{e q}$ is a characteristic angle between edges for an ideal, equilateral element (regular tetrahedron). By definition $0 \leq \mathrm{Q}_{E A S} \leq 1, \mathrm{Q}_{E A S}=0$ describes equilateral elements and $\mathrm{Q}_{E A S}=1$ completely degenerated cells.

In EquiSize Skew criterion $\left(\mathrm{Q}_{E S S}\right)$ the metric of skewness was calculated with equation:

$$
Q_{E S S}=\frac{\left(V_{e q}-V\right)}{V_{e q}}
$$

where: $V$ is volume of cell and $V_{e q}$ is the maximum volume of an equilateral cell described on a sphere with the same volume as the volume of the cell.

The maximum range for both criteria did not exceeds the value of 0.75 and the modal range was also similar (0.3-0.4). Only the percentage of cells in the modal range differed slightly. This is shown in the Table 3 for Grid 2. It confirms that all grids were of good quality $[45,46]$.

During numerical simulations grid density independency test was executed. Tested grids consisted of $1.5 \times 10^{5}, 3 \times 10^{5}$ and $6.2 \times 10^{5}$ cells. Changes of predicted values and computation time were monitored. The number of cells used in this study was a minimum value for which no changes were observed for predicted quantities and computation time was the shortest. In Table 3 are listed example values of $Q_{E A S}$ and $Q_{E S S}$ criterion for grids. Regardless of the number of mesh elements, their quality parameters are similar with the modal value in the range of $0.3 \div 0.4$ and the percentage of cells in this range of about $40 \%$ $\left(\mathrm{Q}_{E A S}\right)$ and about $35 \%\left(\mathrm{Q}_{E S S}\right)$. The maximum values in both cases do not exceed 0.75 and there are very few elements for the last range $(0.7 \div 0.75)$, well below $1 \%$. It proves good quality of grids.

Table 3. Grid quality parameters and mean differences for predicted quantities.

\begin{tabular}{cccccc}
\hline Grid Symbol & Number of Cells & $\begin{array}{c}\text { Modal Value } \\
\left(\mathbf{Q}_{E A S}\right)\left(\mathbf{Q}_{E S S}\right)\end{array}$ & $\begin{array}{c}\text { Maximum Value } \\
\left(\mathbf{Q}_{E A S}\right)\left(\mathbf{Q}_{E S S}\right)\end{array}$ & $\begin{array}{c}\text { Mean Difference } \\
\text { (Velocity) [\%] }\end{array}$ & $\begin{array}{c}\text { Mean Difference } \\
\text { (Pressure) [\%] }\end{array}$ \\
\hline Grid 1 & 157144 & $0.3 \div 0.4(41.8 \%)$ & $0.7 \div 0.75(0.17 \%)$ & $23.7 \div 32.1$ & $18.4 \div 28.9$ \\
& & $0.3 \div 0.4(36.3 \%)$ & $0.7 \div 0.75(0.24 \%)$ & & - \\
\hline Grid 2 & \multirow{2}{*}{ (209 258 } & $0.3 \div 0.4(40.5 \%)$ & $0.7 \div 0.75(0.19 \%)$ & - & $5.5 \div 7.3$ \\
\hline Grid 3 & & $0.3 \div 0.4(34.7 \%)$ & $0.7 \div 0.75(0.26 \%)$ & & \\
& \multirow{2}{*}{626750} & $0.3 \div 0.4(38.4 \%)$ & $0.7 \div 0.75(0.22 \%)$ & $6.7 \div 9.3$ & \\
\hline
\end{tabular}

Figure 4 presents the change of predicted parameters (mean gas velocity, total gas pressure) for grids of different density. Both for velocity and pressure, the simulation results for the Grid 1 (coarse grid) differ from the Grid 2 (medium grid) and the Grid 3 (fine grid). The differences are both in terms of quality (course of curves) and quantity (values). The values of mean differences, estimated for all analyzed cyclone cross-section planes for Grid 1 and Grid 3 in relation to Grid 2 are listed in Table 3. The mean differences between results for Grid 2 and Grid 3 are slight and not exceed $10 \%$. In the comparison of Grid 2 and Grid 1, differences are greater and amount to $20 \div 30 \%$. Therefore, the most advantageous, both in terms of the stability of results and the time of calculations, is the choice of Grid 2 and this was done in the conducted research. 
a)

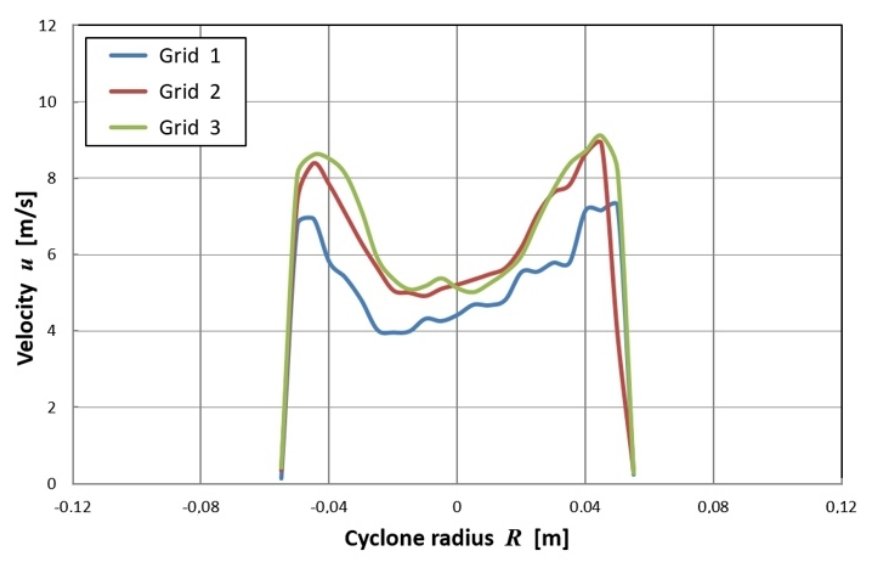

b)

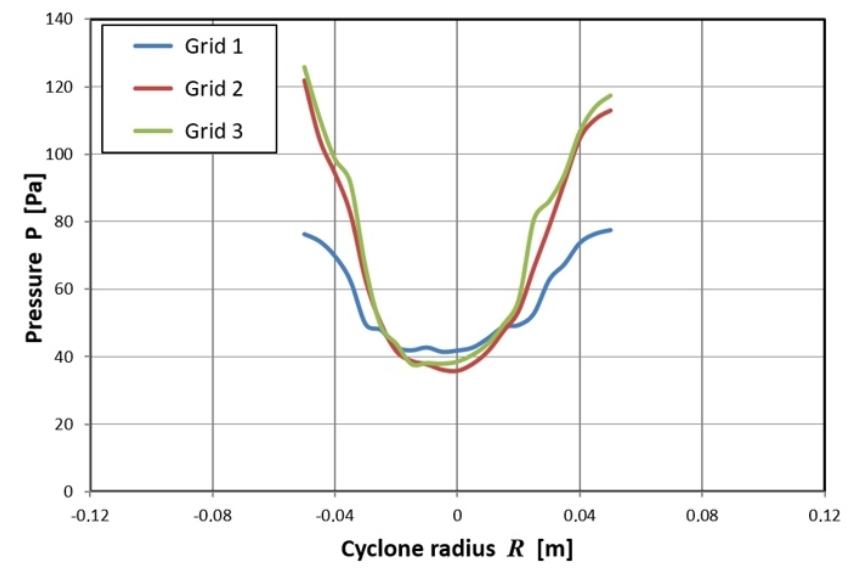

Figure 4. The changes of (a) velocity magnitude, (b) total pressure for grids of different density.

The simulations were carried out with the use of the steady state CFD model. The partial, differential equations of the model were discretized with the use of the finite volume (FV) method. The SIMPLE (Semi-Implicit Method for Pressure Linked Equations) algorithm was applied for pressure-velocity coupling, PRESTO! (Pressure Staggered Option) was chosen as a spatial discretization for pressure and Second Order Upwind mode was used for discretization of momentum, turbulent kinetic energy and energy dissipation rate. These are common solution methods, used by most authors [7,9,11,13,19] who conduct CFD simulations of cyclone separators and they give good enough agreement between simulations and measurements. Moreover, in simulations the convergence criteria were as follows: scaled residuals were below $10^{-6}$ and main, determined quantities (velocity, pressure, turbulence parameters) were constant.

Turbulent flow in the cyclone was described using the Navier-Stokes equations of mass and momentum transport, averaged by Reynolds method (RANS) [44,49]. As a closing method, the RNG (Renormalization Group) k- $\varepsilon$ turbulence model [50,51] was selected, with an additional option of the RNG-Swirl Dominated Flow [47], taking into account a strong vorticity nature of flow inside the cyclone.

To simulate the motion of the discrete phase (particles), the Discrete Phase Model (DPM) was used. In this procedure the Euler-Lagrange (EL) approach is applied [52]. In this approach a flow of the continuous phase (gas) is solved using averaged transport Navier-Stokes equations, while dispersed phase (particles) motion is modelled by solving motion equations for each particle individually. Euler-Lagrange model can be applied for low concentrations of dispersed phase (usually less than $12 \%$ vol.) [9]. In our simulations particles volume fraction was indicatively less than $5 \%$ by volume, therefore an influence of particle-particle collisions and their collisions with apparatus wall on the momentum transfer in the mixture can be neglected.

\section{Validation of Numerical Model by Anemometry Measurements}

The validation of CFD simulation results and numerical models was carried out with the use of hot-wire anemometry technique. This is one of three measuring methods next to LDA anemometry and Pitot-probe, used to identify the flow in cyclone separators [5,13,27,53,54].

Measurements were conducted using two-channel, constant temperature anemometer MiniCTA 54T30 Dantec Dynamic [55].Validation by anemometry measurements was carried out for the numerical model of cyclone I (basic model, Figure 2a).

The probe was positioned perpendicular to the vertical cross-section plane of the cyclone (XZ plane) and its tip was located in this plane. Which enabled measurement of the mean, tangential velocity of rotating gas. Small dimensions of the probe did not significantly disturb the gas flow in the cyclone. The measurement error (relative expanded uncertainty) taking into 
account such uncertainties as [56]: calibration/linearization, data acquisition and uncertainties related to experimental conditions was estimated at about $2.6 \%$.

Measurements were carried out at three different heights in the cyclone, according to horizontal, cross-section planes $z_{1}, z_{3}$ and $z_{4}$ (Figure 1). Measuring points are arranged along horizontal lines, their arrangement is shown in Figure 5 (front and back view of the cyclone), and their radial coordinates, along the $\mathrm{X}$ axis are presented in Table 4.

a)

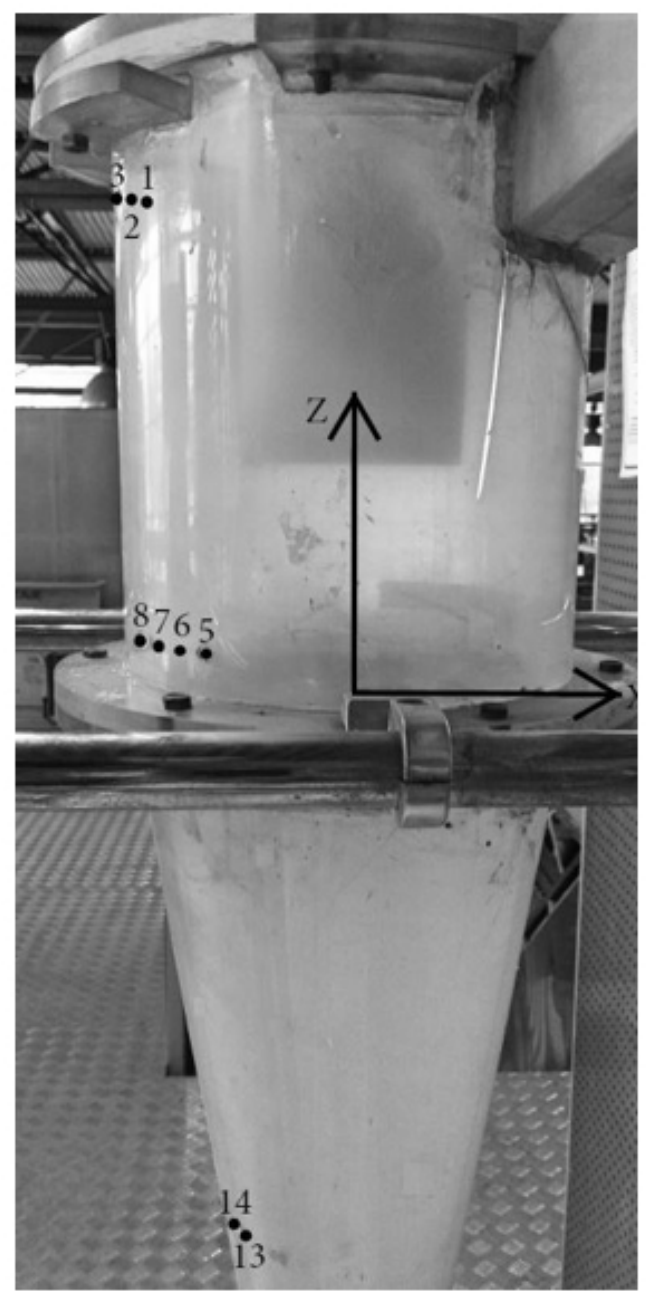

b)

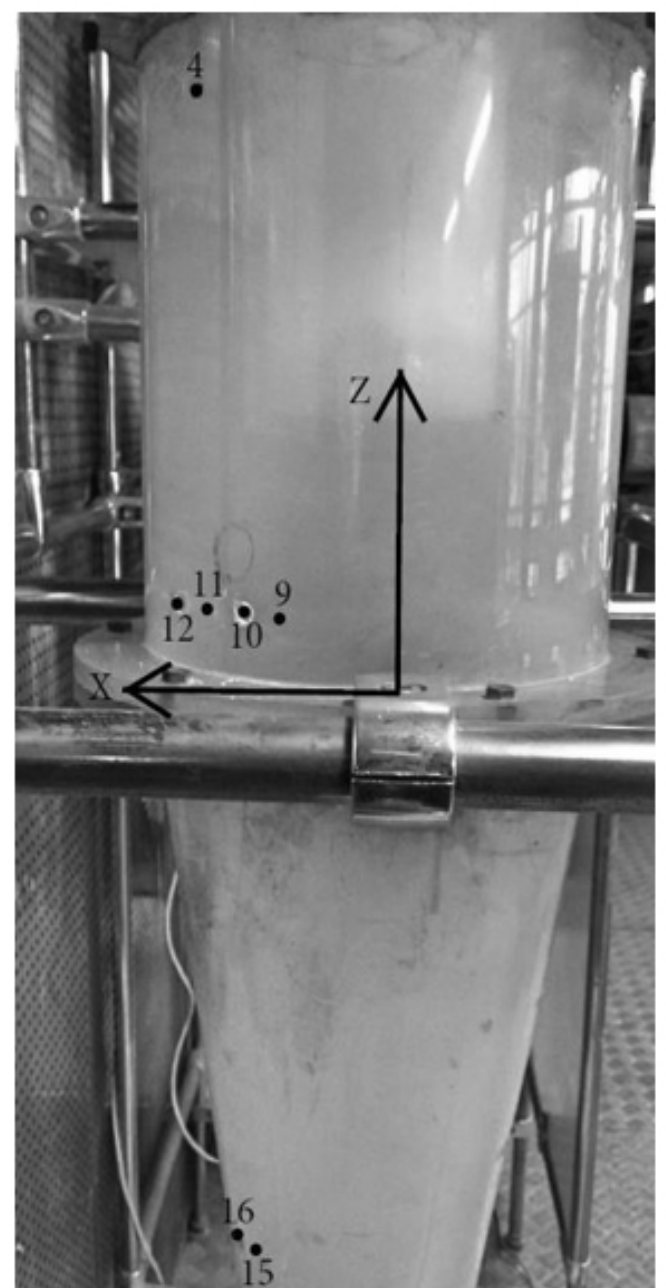

Figure 5. Arrangement of measuring points in the cyclone (a) cyclone front view, (b) cyclone back view.

Figure 6 and Table 4 present a comparison of the results obtained from simulations and hot-wire, anemometric measurements. Table 4 summarizes numerical values of the mean, tangential gas velocity, determined by both methods and also presents values of average relative errors. 


\section{a) $\mathrm{Z}_{1}$-plane}

- Simulations $\Delta$ Measurements

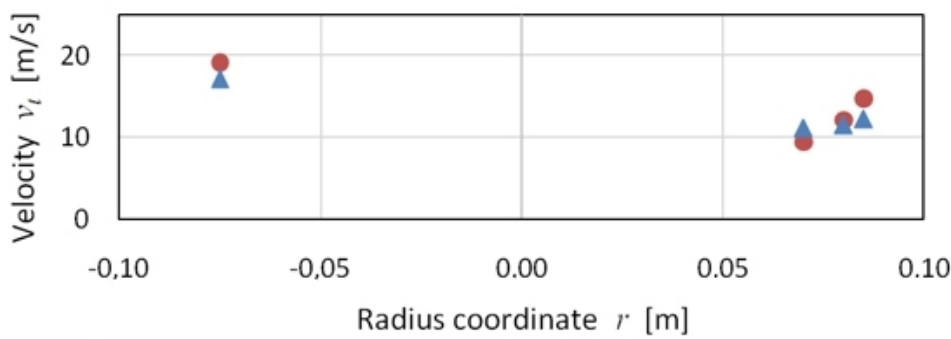

b) $z_{3}$-plane

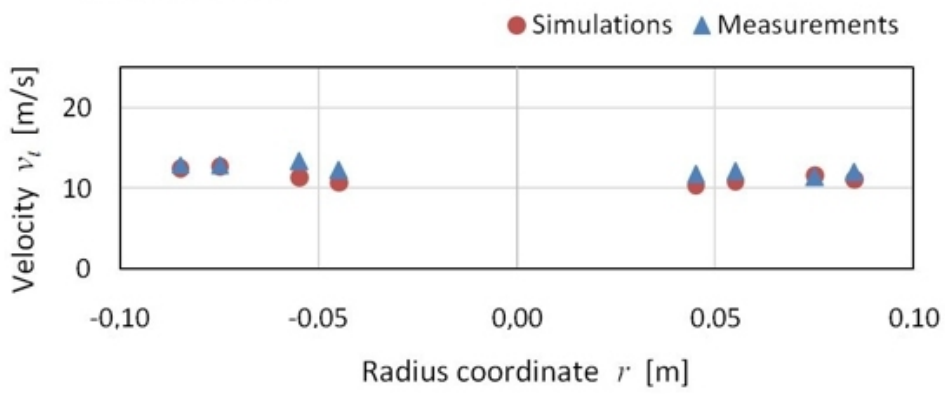

c) $z_{4}$-plane

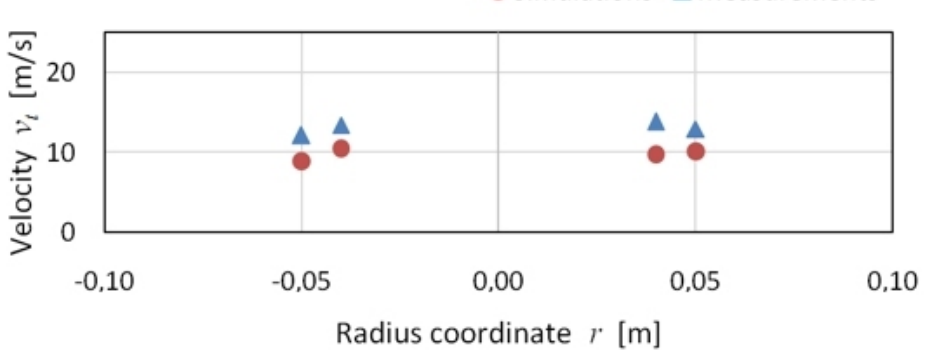

Figure 6. Comparison of simulated and measured data for analyzed points located along cyclone cross-sectional planes: (a) $z_{1}$-plane, (b) $z_{3}$-plane, (c) $z_{4}$-plane.

The comparison shows a relatively good agreement of simulation and measurement results, taking into account the very complex nature of the gas flow in the cyclone. In three analyzed zones, the best agreement of results was observed in the tip of barrel where the relative error was in the range of $\Delta=0.9 \div 14.5 \%$ (its mean value in this zone was $\bar{\Delta}=7.8 \%$ ). Equally low relative errors were determined in the upper part of the cyclone, in the vicinity of the vortex finder. Their range was $\Delta=5.6 \div 14.9 \%$ and mean value $\bar{\Delta}=11.7 \%$ ). The largest differences were determined in the cone, where the relative error values belonged to the range of $\Delta=21.1 \div 28.7 \%$ and their mean values $\bar{\Delta}=24.4 \%$. The discrepancies in this zone may arise-as shown in following simulations-from specifics of gas flow in the cone, strong mixing of gas streams and the imposition of outer and inner vortex in a relatively narrow area. This can cause both simulation and measurement errors in this region.

However, taking into account the complicated nature of the gas flow in cyclone separators, it can be stated that the determined differences between simulations and measurements are acceptable, and numerical models proposed and used in this work can be used in both engineering and practical applications as well as scientific research. This is also confirmed by the results of simulations and measurements of pressure drop presented later in this work. 
Table 4. Comparison of simulated and measured data of gas tangential velocity in the cyclone.

\begin{tabular}{ccccc}
\hline Point Number & Radial Coordinate [m] & $\begin{array}{c}\text { Tangential Velo- } \\
\text { city Simulated [m/s] }\end{array}$ & $\begin{array}{c}\text { Tangential Velo- } \\
\text { city Measured [m/s] }\end{array}$ & Relative Error [\%] \\
\hline 1 & 0.075 & 9.47 & 11.13 & 14.9 \\
2 & 0.080 & 12.15 & 11.46 & 5.7 \\
3 & 0.085 & 14.79 & 12.92 & 14.4 \\
4 & -0.075 & 19.16 & 17.11 & 11.9 \\
\hline 5 & 0.045 & 10.43 & 11.75 & 11.2 \\
6 & 0.055 & 10.93 & 12.15 & 2.1 \\
7 & 0.075 & 11.64 & 11.39 & 7.4 \\
8 & 0.085 & 11.14 & 12.03 & 12.6 \\
10 & -0.045 & 10.72 & 12.27 & 14.5 \\
11 & -0.055 & 11.40 & 13.33 & 0.9 \\
12 & -0.075 & 12.72 & 12.94 & 3.3 \\
13 & -0.085 & 12.51 & 13.82 & 28.7 \\
16 & 0.040 & 9.84 & 12.93 & 21.1 \\
\end{tabular}

\section{Results and Discussion}

\subsection{Flow Pattern and Gas Velocity}

The visualization of flow in examined cyclones was conducted, with so-called $Q-$ criterion, defined as [57]:

$$
Q={ }_{2}^{1}\left(|\Omega|^{2}-|S|^{2}\right)>0
$$

where $\Omega$ is the vorticity tensor and $S$ is the rate-of-strain tensor:

$$
\begin{gathered}
\Omega_{i j}=\frac{1}{2}\left(\frac{\partial u_{i}}{\partial x_{j}}-\frac{\partial u_{j}}{\partial x_{i}}\right) \\
S_{i j}=\frac{1}{2}\left(\frac{\partial u_{i}}{\partial x_{j}}-\frac{\partial u_{j}}{\partial x_{i}}\right)
\end{gathered}
$$

This criterion is often used to identify the cores of vortices, their location and scale, that are formed in various equipment of process engineering, including energy production apparatuses and dust separators [38,40].

Example visualizations of vortices formed in cyclones are presented in Figure 7. To enable comparisons of cyclones, visualizations were made with fixed, appropriate values of $Q$-criterion iso-surfaces, colored by velocity magnitude.

The images show two different types of vortices, forming in cyclones. The main (outer) vortex, with scale (diameter) comparable to the cyclone barrel (Figure 7 top raw), participating in the dust removal process, where particles are separated, and a smaller-scale (inner) vortex, where a stream of purified gas leaving the cyclone (Figure 7, bottom raw). Its diameter is close to that of the vortex finder and it is forming in the cyclone center, close to cyclone vertical axis.

For each of cyclones, the scale and location of the main vortex are similar, but the range of the first spiral, generated immediately after the inlet changes. The smallest height of the first spiral (its shortening) is observed for the cyclone with the shortest vortex finder (cyclone III), therefore it can be assumed that shortening this length will generate just such an effect. Moreover, at this inlet velocity in all tested cyclones, a slight gas flow is generated in the dust hopper, which may cause re-entrainment of the smallest, previously deposited particles. 

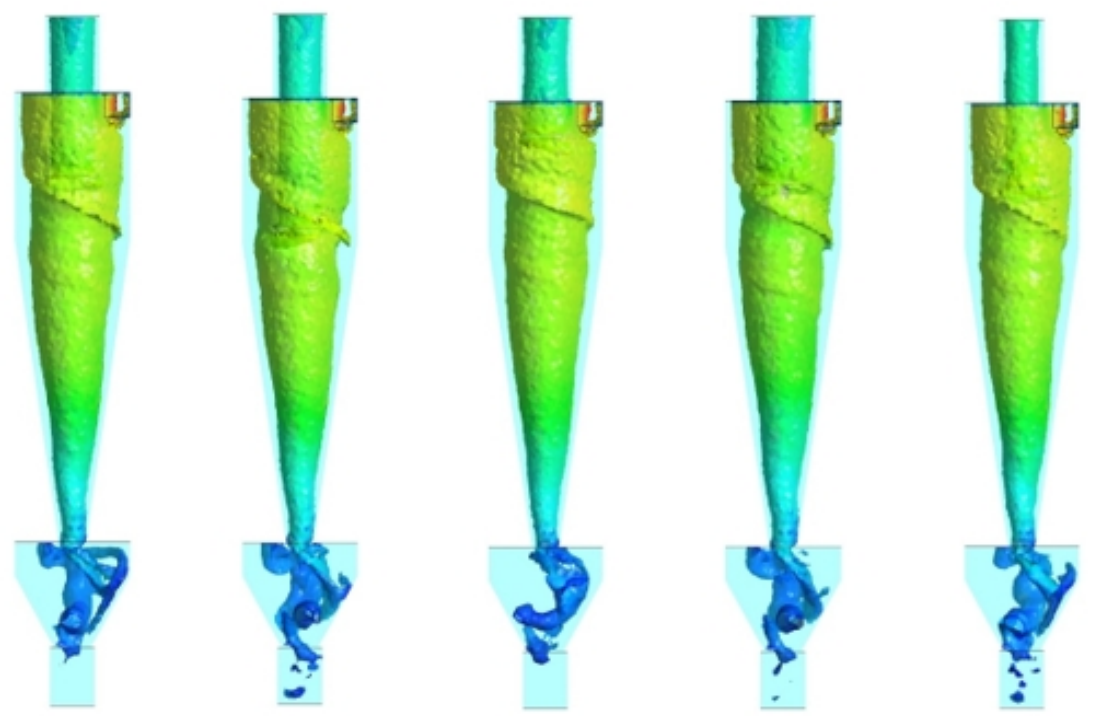
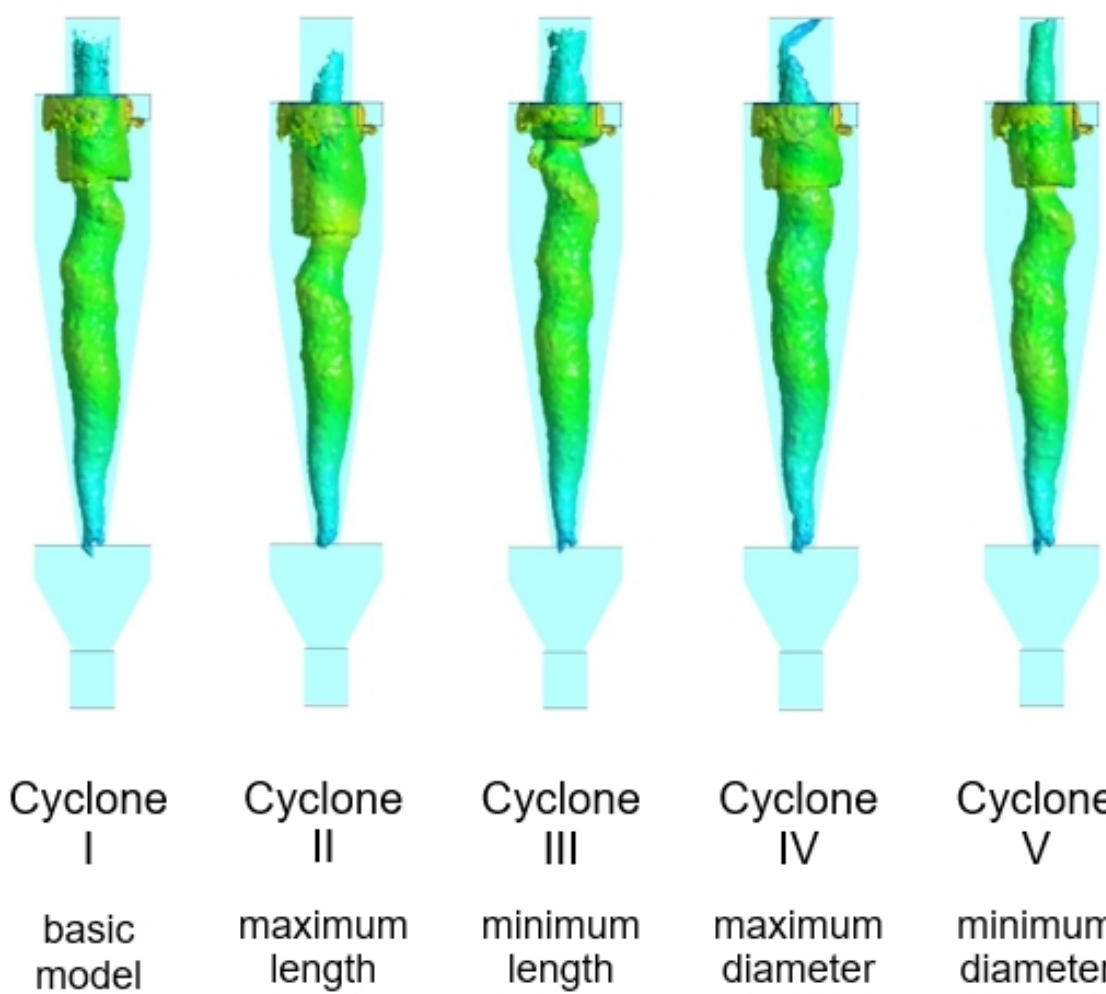

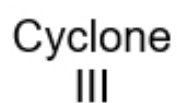

\section{minimum} length

\section{Cyclone} IV

\section{maximum diameter}

\section{Cyclone $\mathrm{V}$}

minimum

diameter

Figure 7. Visualization of vortices in cyclones using the $Q$-criterion (outer vortex $Q=1500 \mathrm{~s}^{-2}$, inner vortex $Q=30,500 \mathrm{~s}^{-2}$ ).

As might be expected, the inner vortex shape, scale and location are dependent on the diameter of the vortex finder. In each of cyclones, the scale of the inner vortex in their lower parts is similar, but it changes close to the tip of the vortex finder, from the smallest in the case of the cyclone $\mathrm{V}$ (with the smallest outlet diameter) to the largest in the cyclone IV (with the largest outlet diameter).

In a cyclone with a larger diameter of an outlet (cyclone IV), a disturbance in the flow inside the vortex finder is also observed. In other cyclones the flow in this zone is relatively stable. This is also confirmed by vector maps of flow, shown in Figure 8. 


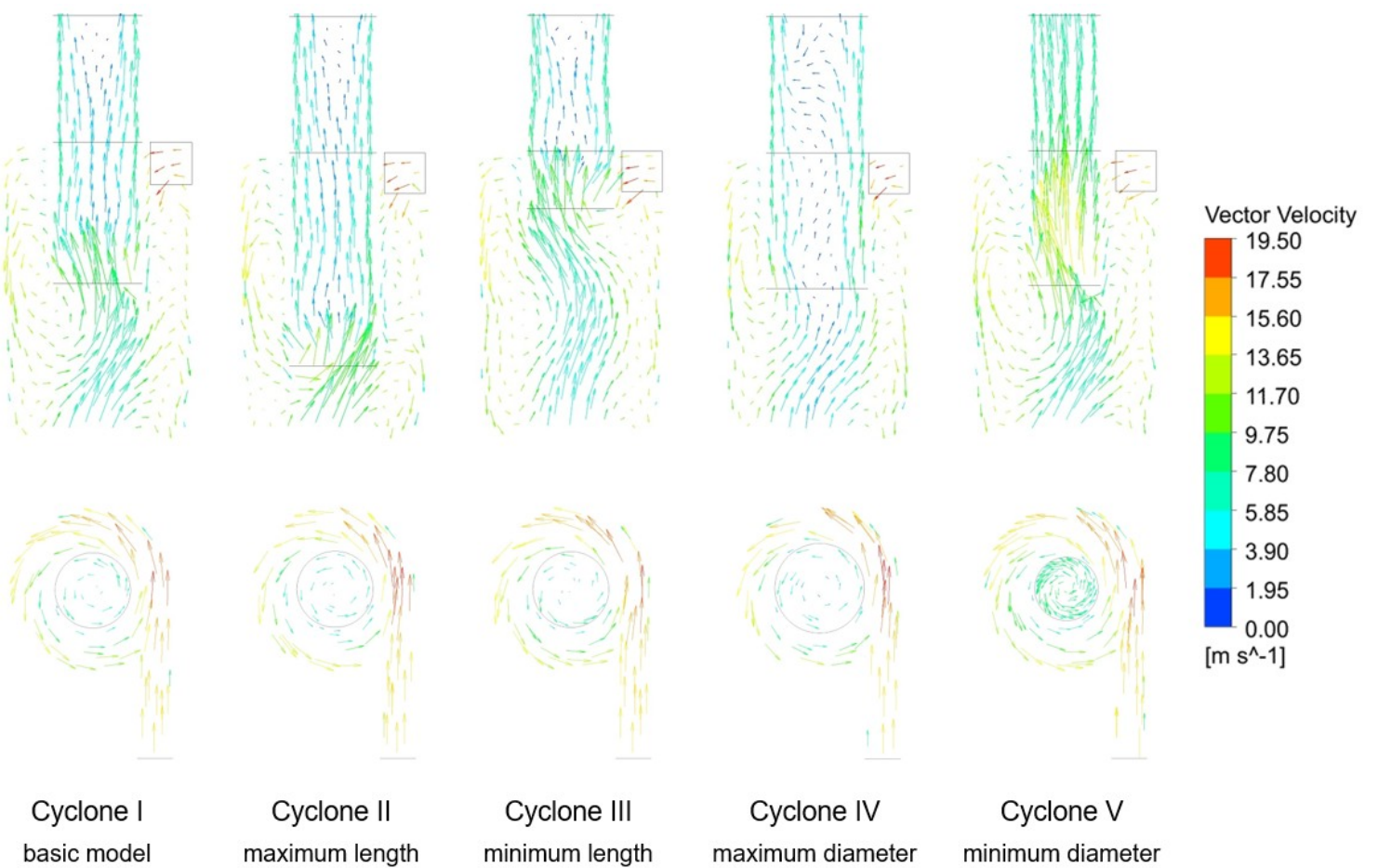

Figure 8. Vector maps of flow in vortex finder zone (axial cross-section and horizontal cross-section along $z_{1}$ - plane).

In cyclone IV, with the largest vortex finder diameter a gas swirls inside the center of the vortex finder and even the gas reverse flow was observed. On the other hand, in a cyclone with an outlet of smallest diameter (cyclone V), as a result of reducing this diameter, there was a significant increase in gas velocity, significantly different from values obtained for other models.

It is also interesting that in all cyclones with standard-length outlet (cyclones I, IV and V), a formed swirl of the gas inlet stream was observed near the tip of the vortex finder. It may trigger a part of the dusty gas to pass directly from the inlet to the outlet. This may reduce the collection efficiency of these cyclones. Similar phenomena were also reported and described in [58]. The lengthening or shortening of the vortex finder can largely eliminate this phenomenon.

The above-described flow pattern is also confirmed by contour maps and graphs, showing predicted distribution of resultant gas velocity (velocity magnitude)—Figures 9 and 10 .

In the first three cyclones (cyclones I, II and III) with outlet of the same diameter, the gas flow is qualitatively similar. However, quantitative differences are predicted for the gas velocity inside vortex finders. In cyclones with an elongated (cyclone II) or shortened (cyclone III) outlet in relation to the basic model, lower gas velocities are observed inside the vortex finder, with a local minimum in the cyclone axis. These minimum values can be even twice lower than those in the basic model (Figure 10a).

Another flow pattern in this top zone is seen for cyclones with a larger (cyclone IV) or smaller (cyclone V) outlet diameter (Figure 10b). In the first of them, a distinct zone of relatively low velocities $(\mathrm{u}=0 \div 4 \mathrm{~m} / \mathrm{s})$ is observed. It is located close to the vertical axis of the cyclone and covers practically the entire height of cyclone, including the vortex finder. In the second of them, with the smallest diameter of the outlet, the flow is completely different. The velocity distribution inside the apparatus is more uniform, and-as a result of the reduction of the vortex finder diameter-there is a significant increase in the gas flow velocity, inside it. The gas flow velocity in the outlet axis is even 2.5 times higher than that of the basic model. 


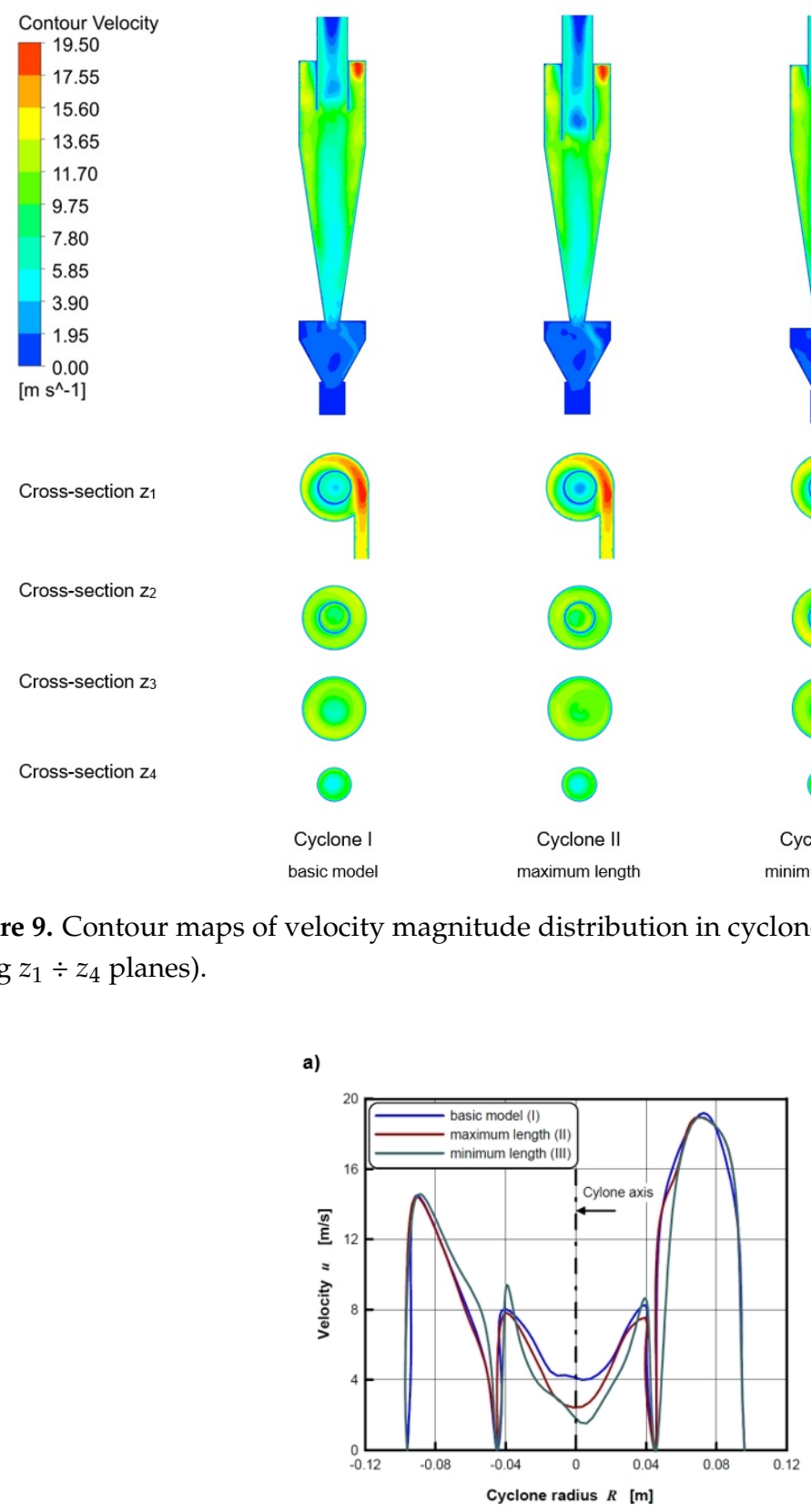

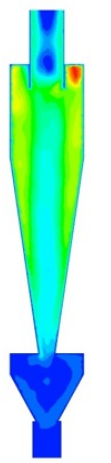
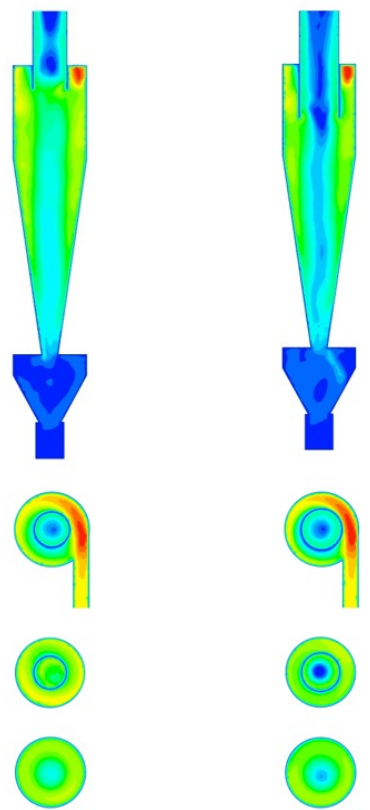

Cyclone III minimum length

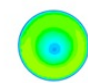

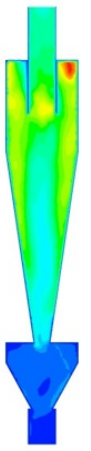
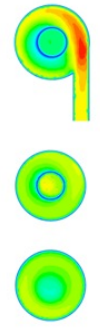

Cyclone V minimum diameter

Figure 9. Contour maps of velocity magnitude distribution in cyclones (axial cross-section and horizontal cross-sections, along $z_{1} \div z_{4}$ planes).

c)

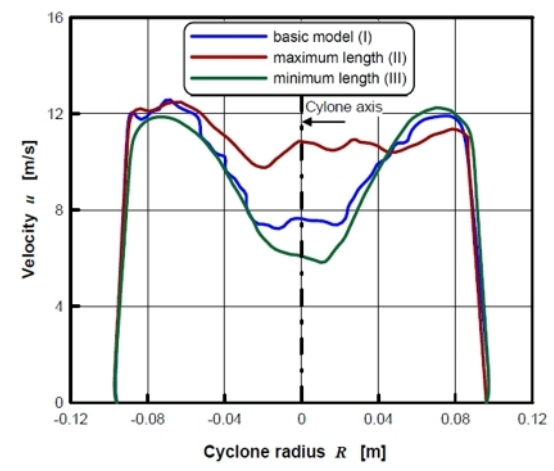

b)

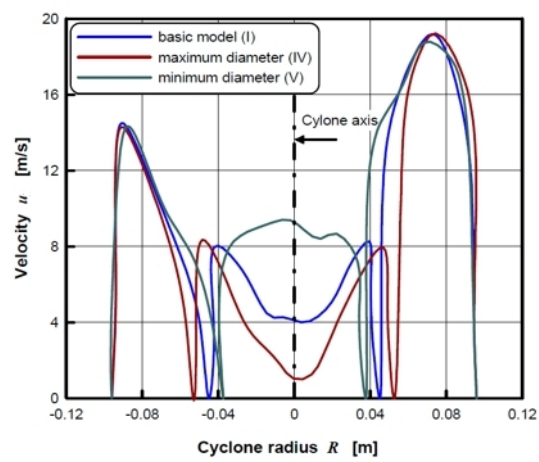

d)

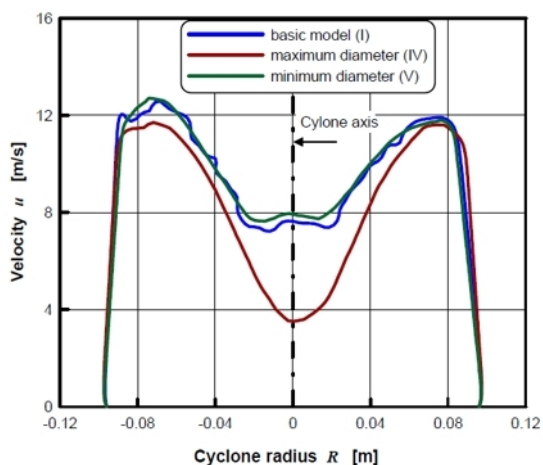

Figure 10. Changes of flow velocity as a function of a cyclone radius: $(\mathbf{a}, \mathbf{b})$-cross-section $z_{1}$-plane ; (c,d)-cross-section $z_{3}$-plane. 
Curves of velocity in cross-section plane $\mathrm{z}_{3}$ (Figure 10c,d) for all cyclones are similar, and have the so-called inverted $\mathrm{W}$-shaped profile [7,8]. Two, almost symmetrical local maximums are observed close to cyclone wall and minimum in the cyclone axis. For cyclones with the same vortex finder diameter (cyclones I $\div$ III, Figure 10c) values of maximum are very close. However, the minimum values differ-from the largest for cyclone with maximum outlet length to about twice lower when the outlet was the shortest. It can therefore be concluded that the elongation of the outlet intensifies the flow in the exhaust gas stream in this zone.

It is also interesting to compare the velocity profiles for cyclones with the largest (cyclone IV) and smallest (cyclone V) diameter of the vortex finder (Figure 10d). In the analyzed zone of cyclones, the maximum velocity values both in terms of location and values are similar to those in other cyclones, while the minimum values, especially in the case of a cyclone with the largest outlet diameter, differ even by about two times. Thus, it can be seen that increasing the diameter of the vortex finder to the proposed dimensions clearly weakens the flow in the gas stream leaving the cyclone.

Numerical simulations also showed in all cyclones an interesting phenomenon of high gas flow velocities (even higher than the gas inlet velocity) at the connection of the inlet with the barrel (Figure 9, cross-section $z_{1}$ ). It was also reported earlier in or paper [40]. The maximum values of gas flow velocity in this zone for cyclones $\mathrm{I} \div \mathrm{V}$ are respectively: $u=19.1,19.2,19.1,19,18.8 \mathrm{~m} / \mathrm{s}$, which are values of about $25 \div 28 \%$ greater than the inlet velocity. The reason for such an increase in velocity may be a sudden narrowing of the gas stream at the start of its rotation and a significant increase of the tangential component of velocity, crucial for a dust removal process. This tendency was also observed and reported in [9], where the research was focused on classic, Stairmand [12] cyclone and optimized, new design cyclone.

\subsection{Pressure Distribution and Pressure Drop}

Pressure drop is a key parameter for a cyclone separator, which-in connection with the collection efficiency-proves the effectiveness of its operation and the profitability of its application. The basis for determining of the pressure drop for examined cyclones were total pressure distributions, shown in Figures 11 and 12.

It is seen, that total pressure and its distribution depend on geometry of the vortex finder. The maximum vales of the total pressure were observed for the cyclone $V$, the minimum ones in cyclone IV. This tendency is rather obvious and it is related to the diameter of the outlet in these cyclones, respectively the largest and the smallest. It can also be seen that the total pressure distribution in all cyclones has the highest values at the top of separator and low or even underpressure (cyclone IV with the biggest outlet diameter) in a zone close to the cyclone axis.

All curves presented in Figure 12 confirm this quantitatively, profiles have s similar shape (U-shaped profile), with maximum values close to cyclone walls and a local minimum in cyclone axis. The differences between individual models are smaller than those for velocity. For cyclones with the same vortex finder diameter but different lengths (cyclones $\mathrm{I} \div$ III, Figure $12 \mathrm{a}, \mathrm{c}$ ) curves practically coincide and differences are negligible. Slight discrepancies are observed when outlet diameters are changed (cyclones IV and cyclone V, Figure $12 \mathrm{~b}, \mathrm{~d}$ ). Minimum values of total pressure in a cyclone axis for these models differ by about 10 times, with even underpressure for cyclone $\mathrm{V}$. 


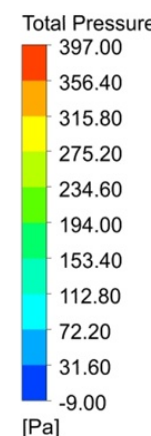

Cross-section z1

Cross-section z2

Cross-section z3

Cross-section z4
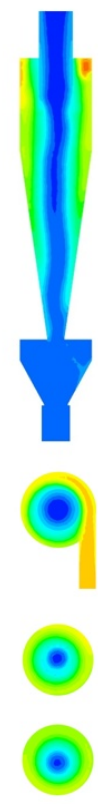

Cyclone I basic model
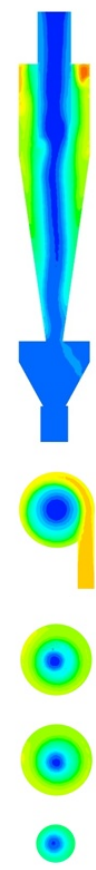

Cyclone II maximum length
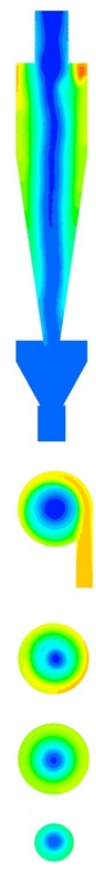

Cyclone III minimum length
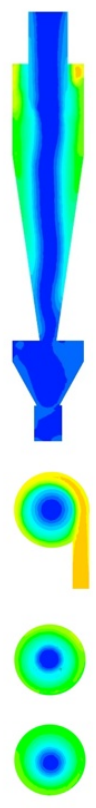

Cyclone IV maximum diameter
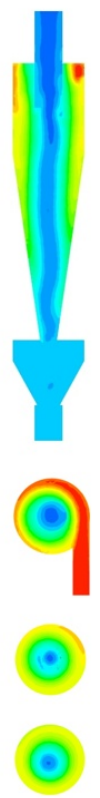

(e)

Cyclone V minimum diameter

Figure 11. Contour maps of total pressure distribution in cyclones (axial cross-section and horizontal cross-sections, along $z_{1} \div z_{4}$ planes).

a)

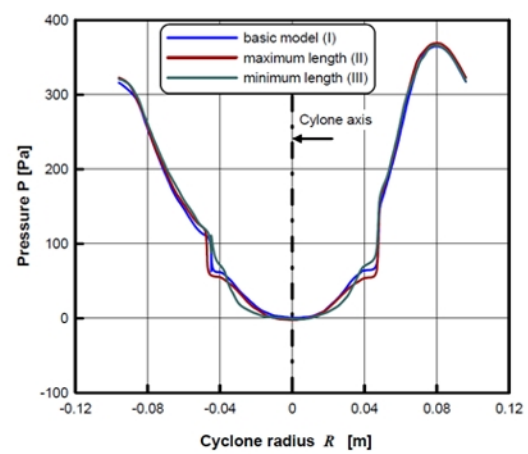

c)

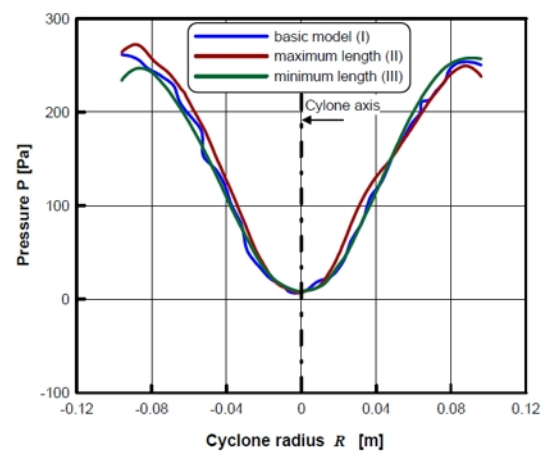

b)

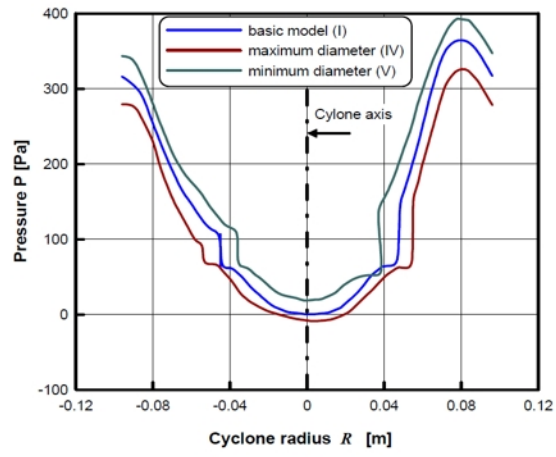

d)

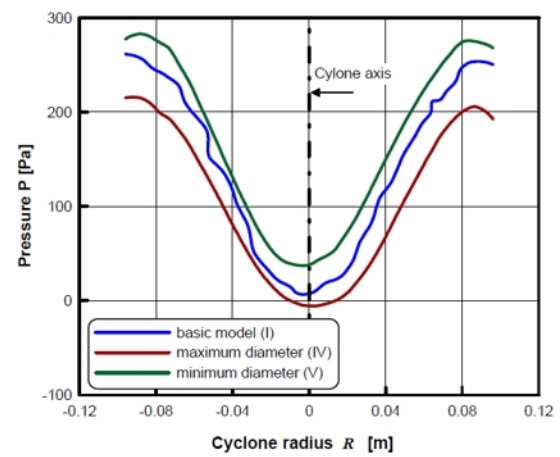

Figure 12. Changes of a total pressure as a function of a cyclone radius; (a,b)-cross-section $z_{1}$-plane, (c,d)-cross-section $z_{3}$-plane . 
It can be concluded that for tested cyclones the impact of the length of the vortex finder on the total pressure distribution is less significant than an influence of its diameter. This is also confirmed by the quantitative data shown in Table, determined on the basis of simulations, measurements and empirical correlation.

In simulations the pressure drop for cyclones was determined on the basis of the difference of averaged values of the total pressure at the entire cross-sectional area of an inlet and the vortex finder (similarly to e.g., in [22,23]). This is a different, but more accurate method, than that used in our earlier work [40], where pressure difference was determined on the basis of point values. In addition—for cyclone I (basic model)—results of simulations were compared to measurement data. The pressure drop for all cyclones was also calculated from empirical Coker formula [59], which-as shown in previous research [40] - describes well the pressure drop in examined cyclones. This formula is typical- it takes into account an inlet gas velocity $u_{i n}$, gas density $\rho_{c}$ and cyclone geometry:

$$
\Delta p=\alpha \frac{u_{i n}^{2}}{2} \rho_{c}
$$

were $\alpha$ coefficient is determined from the following relationship, taking into account dimensions of the cyclone inlet and outlet:

$$
\alpha=9.47 \frac{a b}{D_{e}^{2}}
$$

As shown by the data presented in Table, the proposed numerical models of cyclones describe both pressure distributions and the pressure drop relatively well.

Table 5. Pressure drop determined for examined cyclones.

\begin{tabular}{ccccc}
\hline \multirow{2}{*}{ Cyclone Model } & \multicolumn{4}{c}{ Pressure Drop, Pa } \\
\cline { 2 - 5 } & CFD Simulation & Coker Eq. [59] & Measurement & Relative Error, \% \\
\hline $\begin{array}{c}\text { Cyclone I } \\
\text { basic model }\end{array}$ & 341 & 284 & 340 & 16.7 \\
\hline $\begin{array}{c}\text { Cyclone II } \\
\text { maximum length }\end{array}$ & 347 & 284 & - & 18.1 \\
\hline $\begin{array}{c}\text { Cyclone III } \\
\text { minimum length }\end{array}$ & 340 & 284 & - & 16.4 \\
\hline $\begin{array}{c}\text { Cyclone IV } \\
\text { maximum diameter }\end{array}$ & 305 & 209 & - & 31.5 \\
\hline $\begin{array}{c}\text { Cyclone V } \\
\text { minimum diameter }\end{array}$ & 358 & 409 & - & 14.3 \\
$*$ in relation to measurements. & & &
\end{tabular}

The tendency for pressure drop is correct and consistent with engineering practicesmall differences in the case of the same outlet diameter and more significant when changing it. Smaller pressure drop values are observed when vortex finder diameter is the largest (cyclone IV) and the largest values for the smallest vortex finder diameter (cyclone V). It is related to smaller and bigger gas flow resistance, respectively.

The pressure drop values, predicted with CFD simulations and measurements for the basic model are practically identical, while in the comparison with values calculated from the Coker correlation the relative error is in the range of $\Delta \approx 16 \div 18 \%$. For cyclones with the same vortex finder diameter but different length (cyclone I $\div$ III) and cyclone with the largest vortex finder diameter (cyclone IV) predicted values are slightly overestimated in comparison with calculated ones (in the last model relative error is greater $\Delta \approx 31 \%$ ). For the cyclone with the smallest diameter of vortex finder (cyclone $\mathrm{V}$ ) the predicted value is slightly underestimated (relative error $\Delta \approx 14 \%$ ). 
It should be noted, however, that the diameters of outlets in cyclones IV and V were selected as the extreme values within the range of values recommended in the literature, which may be the cause of the described errors and discrepancies.

\subsection{Collection Efficiency}

The second important parameter that characterizes the performance of the cyclone is collection efficiency. In the conducted simulations, it was determined as the ratio of the amount of particles of a specific size range deposited in the cyclone to the amount of all particles introduced into the cyclone with the gas. The collection efficiencies predicted numerically for examined variants of the vortex finder are listed in the Table 6. Additionally, in the case of cyclone I (basic model) its value was compared with the value determined experimentally.

Table 6. Collection efficiency for examined cyclones.

\begin{tabular}{cccc}
\hline \multirow{2}{*}{ Cyclone Model } & \multicolumn{3}{c}{ Collection Efficiency, \% } \\
\cline { 2 - 4 } & CFD Simulation & Measurement & Relative Error, \% \\
\hline $\begin{array}{c}\text { Cyclone I } \\
\text { basic model }\end{array}$ & 86.3 & 87.8 & 1.7 \\
\hline $\begin{array}{c}\text { Cyclone II } \\
\text { maximum length }\end{array}$ & 85.5 & - & - \\
\hline $\begin{array}{c}\text { Cyclone III } \\
\text { minimum length }\end{array}$ & 89.5 & - & - \\
\hline $\begin{array}{c}\text { Cyclone IV } \\
\text { maximum diameter }\end{array}$ & 86.6 & - & - \\
\hline $\begin{array}{c}\text { Cyclone V } \\
\text { minimum diameter }\end{array}$ & 87.7 & - & \\
\hline
\end{tabular}

The numerical model describes well the real collection efficiency of the cyclone (the relative error is $1.7 \%$ ). All cyclones operate with relatively high collection efficiency, within the range $85.5 \div 89.5 \%$. The highest efficiency was determined for the cyclone with the shortest length of the vortex finder (cyclone III), the lowest for the cyclone with the longest outlet (cyclone II). The combination of these data with visualizations of the flow pattern (Section 5.1) shows that shortening the length of a vortex finder increases the efficiency of collection, while its elongation reduces this efficiency. When the diameter of the outlet was changed, differences were smaller (about 1\%). The change in the length of the outlet, not its diameter, can have a significant impact on the efficiency of collection in the cyclone.

\section{Conclusions}

The study described in this paper was focused on determination of flow pattern, pressure distribution, pressure drop and collection efficiency for the cyclone separator with a square inlet and different dimensions of a vortex finder. The analysis was carried out on the basis of results of CFD simulations, measurements and values calculated from literature, empirical correlations.

This study demonstrated that:

1. In cyclones of this kind the choice of a vortex finder geometry has an influence on their operation. It was observed both for the flow model, pressure drop and collection efficiency.

2. Numerical simulations and flow visualizations obtained from them, made it possible to determine the position, scale, range and intensity of outer and inner vortex in cyclones. It has also been shown that the above parameters are related to the geometry (length, diameter) of the vortex finder. 
3. Flow velocity and flow pattern generated in cyclones are determined by the vortex finder geometry. Depending on it, the flow of dusty gas in the outlet and in the cyclone may be entirely different. Increasing the length of the vortex finder (with the same diameter) and reducing its diameter intensifies the gas flow leaving the cyclone. Conversely, shortening the length or increasing the diameter of the outlet reduces the flow.

4. The numerical simulations showed some unfavorable and beneficial effects and phenomena that may occur in cyclones with such design, e.g., disturbed and reverse flow of dusty gas in the outlet, an underpressure in the central part of the cyclone, the possibility of direct flow of dusty gas from the inlet to outlet or an increase in the gas flow velocity above the inlet velocity at the top of the cyclone.

5. The numerical analysis showed that the lowest pressure drop (305 $\mathrm{Pa})$ was for the cyclone with the maximum vortex finder diameter $\left(D_{e}=0.105 \mathrm{~m}\right)$, the highest $(358 \mathrm{~Pa})$ in the cyclone with a minimum diameter $\left(D_{e}=0.075 \mathrm{~m}\right)$. The changes of a vortex finder length did not significantly affect the pressure drop.

6. It is different in the case of the collection efficiency.The highest value of this parameter equal to $89.5 \%$ was determined for the cyclone with a minimum length of the vortex finder $(s=0.060 \mathrm{~m})$. The lowest efficiency $85.5 \%$ was determined for the cyclone with the maximum outlet length $(s=0.220 \mathrm{~m})$. The influence of the diameter of the vortex finder on the collection efficiency was less significant.

7. As shown by presented data and comparisons with theory and experiments, the proposed numerical models of cyclones describe well the flow (flow pattern, velocity values), pressure (pressure distribution, pressure drop) as well as collection efficiency. The consistency is observed in terms of quality as well as quantity. The results are also consistent with research results and engineering practice.

Utilitarian effects of these investigations can be used to describe processes and phenomena occurring in cyclone separators as well as during designing and engineering optimization of apparatuses of this kind. However, it is necessary to conduct further research, particularly in the range of analysis into two-phase flow in these cyclones, e.g., detailed analysis of the movement of solid particles inside the cyclone, their mutual interactions and undesirable phenomena as well as numerical and experimental analysis of collection efficiency for other gas inlet velocities. Only this will allow to obtain a full model of cyclone performance and to choose an optimal, effective design due to both pressure drop and its dust removal efficiency.

Author Contributions: R.W.: Developed a research concept, conducted numerical simulations and measurements, analyzed results also prepared manuscript in the experimental and substantive and descriptive part. P.W.: Conducted numerical simulations, processed data of simulations and analyzed results, prepared graphs and manuscript in the experimental part. A.W.-W.: Processed data of simulations, prepared the manuscript in terms of graphics and editing, also did final proofreading. All authors have read and agreed to the published version of the manuscript.

Funding: This research received no external funding.

Institutional Review Board Statement: Not applicable.

Informed Consent Statement: Not applicable.

Data Availability Statement: Data is contained within the article.

Conflicts of Interest: The authors declare no conflict of interest.

\section{References}

1. Clift, R.; Seville, J.P.K. Gas Cleaning at High Temperatures; Springer-Science + Business Media: Berlin, Germany, 1993.

2. Seville, J.P.K. Gas Cleaning in Demanding Applications; Springer: Dordrecht, The Netherlands, 2013.

3. Wójtowicz-Wróbel, A. Thermal waste processing system structures. Questions of locations and accessibility-Polish experiences. In Nuclear technologies recycling air pollution and climate change. In Proceedings of the 17th International Multidisciplinary Scientific Geoconference SGEM 2017, Albena, Bulgaria, 29 June-5 July 2017; STEF92 Technology Ltd.: Albena, Bulgaria, 2017; Volume 17, pp. 261-268. [CrossRef] 
4. Wójtowicz-Wróbel, A. From a vision to a necessity-from a necessity to a vision. Thermal Waste Processing Plants-Case Study Italy. In Proceedings of the IOP Conference Series: Materials Science and Engineering 3'rd World Multidisciplinary Civil Engineering, Architecture, Urban Planning Symposium (WMCAUS 2018), Prague, Czech Republic, 18-22 June 2018; IOP Publishing: Bristol, UK, 2019; Volume 471, pp. 1-9. (on-line) [CrossRef]

5. Hoffmann, A.C.; Stein, L.E. Gas Cyclones and Swirl Tubes. Principles, Design and Operation; Springer: Berlin, Germany, 2008.

6. Warych, J. Gas Cleaning; WNT: Warsaw, Poland, 1998.

7. Elsayed, K.; Lacor, C. The effect of the dust outlet geometry on the performance and hydrodynamics of gas cyclones. Comput. Fluids 2012, 68, 134-147. [CrossRef]

8. Elsayed, K.; Lacor, C. Numerical modeling of the flow field and performance in cyclones of different cone-tip diameters. Comput. Fluids 2011, 51, 48-59. [CrossRef]

9. Elsayed, K.; Lacor, C. Optimization of the cyclone separator geometry for minimum pressure drop using mathematical models and CFD simulations. Chem. Eng. Sci. 2010, 65, 6048-6058. [CrossRef]

10. Elsayed, K.; Lacor, C. The effect of cyclone vortex finder dimensions on the flow pattern and performance using LES. Comput. Fluids 2013, 71, 224-239. [CrossRef]

11. Brar, L.S.; Sharma, R.P.; Elsayed, K. The effect of cyclone length on the performance of Stairmand high-efficiency cyclone. Powder Technol. 2015, 286, 668-677. [CrossRef]

12. Stairmand, C.J. The design and performance of cyclone separators. Ind. Eng. Chem. 1951, 29, 356-383.

13. Safikhani, H.; Akhavan-Behabadi, M.A.; Shams, M.; Rahimyan, M.H. Numerical simulation of flow field in three types of standard cyclone separators. Adv. Powder Technol. 2010, 21, 435-442. [CrossRef]

14. Surmen, A.; Avci, A.; Karamangil, M.I. Prediction of the maximum-efficiency cyclone length for a cyclone with a tangential entry. Powder Technol. 2011, 207, 1-8. [CrossRef]

15. Bogodage, S.G.; Leung, A.J.T. CFD simulation of cyclone separators to reduce air pollution. Powder Technol. 2015, 286, 488-506. [CrossRef]

16. Raoufi, A.; Shams, M.; Farzaneh, M.; Ebrahimi, R. Numerical simulation and optimization of fluid flow in cyclone vortex finder. Chem. Eng. Prog. 2008, 47, 128-137. [CrossRef]

17. El-Batsh, H.M. Improving cyclone performance by proper selection of the exit pipe. Appl. Math. Model. 2013, 37, 5286-5303. [CrossRef]

18. Talbi, K.; Nemouchi, Z.; Donnot, A.; Belghar, N. An experimental study and a numerical simulation of the turbulent flow under the vortex finder of a cyclone separator. J. Appl. Fluid Mech. 2011, 4, 69-75.

19. Pei, B.; Yang, L.; Dong, K.; Jiang, Y.; Du, X.; Wang, B. The effect of cross-shaped vortex finder on the performance of cyclone separator. Powder Technol. 2017, 313, 135-144. [CrossRef]

20. Su, Y.; Zhao, B.; Zheng, A. Simulation of turbulent flow in square cyclone separator with different gas exhaust. Ind. Eng. Chem. Res. 2011, 50, 12162-12169. [CrossRef]

21. Houben, J.J.H.; Weiss, C.H.; Brunnmair, E.; Pirker, S. CFD simulations of pressure drop and velocity field in a cyclone separator with central vortex stabilization rod. J. Appl. Fluid Mech. 2016, 9, 487-499. [CrossRef]

22. Misiulia, D.; Andersson, A.G.; Lundström, T.S. Computational investigation of an industrial cyclone separator with helical-roof inlet. Chem. Eng. Technol. 2015, 38, 1425-1434. [CrossRef]

23. Misiulia, D.; Andersson, A.G.; Lundström, T.S. Effect of the inlet angle on the flow pattern and pressure drop of a cyclone with helical-roof inlet. Chem. Eng. Res. Des. 2015, 102, 307-321. [CrossRef]

24. Fu, P.-B.; Wang, F.; Yang, X.-J.; Ma, L.; Cui, X.; Wang, H.-L. Inlet particle-sorting cyclone for the enhancement of PM 2.5 separation. Environ. Sci. Technol. 2017, 51, 1587-1594. [CrossRef]

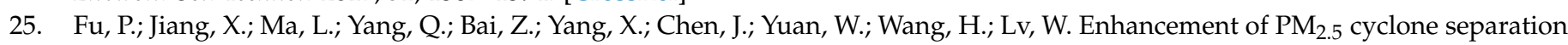
by droplet capture and particle sorting. Environ. Sci. Technol. 2018, 52, 11652-11659. [CrossRef]

26. Qiu, Y.; Deng, B.; Kim, C.N. Numerical study of the flow field and separation efficiency of a divergent cyclone. Powder Technol. 2012, 217, 231-237. [CrossRef]

27. Li, Q.; Xu, W.; Wang, J.; Jin, Y. Performance evaluation of a new cyclone separator - Part I experimental results. Sep. Purif. Technol. 2015, 141, 53-58. [CrossRef]

28. Xu, W.; Li, Q.; Wang, J.; Jin, Y. Performance evaluation of a new cyclone separator - Part II simulation results. Sep. Purif. Technol. 2016, 160, 112-116. [CrossRef]

29. Xiong, Z.; Ji, Z.; Wu, X. Development of a cyclone separator with high efficiency and low pressure drop in axial inlet cyclones. Powder Technol. 2014, 253, 644-649. [CrossRef]

30. Luan, Y.; Sun, H. Experimental and numerical study on the resistance performance of an axial flow cyclone separator. Math. Probl. Eng. 2015, 2015, 1-9. [CrossRef]

31. Avagianos, I.; Vounatsos, P.; Papandreou, I.; Maier, J.; Grammelis, P.; Kakaras, E. Nanoparticle Emission and Characterization from Pre-Dried Lignite and Bituminous Coal Co-Combustion. Energies 2020, 13, 2373. [CrossRef]

32. Liu, X.; Chang, P.; Wang, E.; Zhang, Z.; Yang, S. Numerical Study of the Respirable Coal Dust Removal Performance of a Vortex Ventilation System at an Excavation Face. Energies 2018, 11, 2449. [CrossRef]

33. Tang, C.; Kim, Y.-J. CFD-DEMSimulation for the Distribution and Motion Feature of Solid Particles in Single-Channel Pump. Energies 2020, 13, 4988. [CrossRef] 
34. Lipin, A.A.; Lipin, A.G.; Wójtowicz, R. On the possibility of using combined polymerization and drying in synthesis of polyacrylamide. Chem. Eng. Commun. 2019, 206, 754-760. [CrossRef]

35. Orazbayev, B.; Kozhakhmetova, B.; Wójtowicz, R.; Krawczyk, J. Modeling of a Catalytic Cracking in the Gasoline Production Installation with a Fuzzy Environment. Energies 2020, 13, 4736. [CrossRef]

36. Wójtowicz, R. Flow pattern and power consumption in a vibromix-er. Chem. Eng. Sci. 2017, 172, 622-635. [CrossRef]

37. Wójtowicz, R. Choice of an optimal agitated vessel for the draw-down of floating solids. Ind. Eng. Chem. Res. 2014, 53, 13989-14001. [CrossRef]

38. Wójtowicz, R. Numerical and Experimental Analysis of Vibromixing Selected Issues (Monograph); Cracow University of Technology Publ.: Cracow, Poland, 2019. (In Polish)

39. Prikhodko, A.A. Kinetostatics of rotationally reciprocating stirred tank planetary actuator. In Proceedings of the 5th International Conference on Industrial Engineering (ICIE 2019), 12-14 December 2019; Springer AG: Berlin/Heidelberg, Germany, 2020; Volume 1, pp. 359-366. [CrossRef]

40. Wójtowicz, R.; Wolak, P. An example of the use of Computational-Fluid-Dynamics analysis for simulation of two-phase flow in a cyclone with tangential inlet. Environ. Prot. Eng. 2016, 42, 109-123. [CrossRef]

41. Krawczyk, J.; Szatko, W.; Postnikova, I.; Blinichev, V. Influence of the main factors on the efficiency of wet vortex dust collectors. Izv. Vyss. Uchebnykh Zaved. Khimiyai Khimicheskaya Tekhnologiy 2019, 62, 98-105.

42. Krawczyk, J.; Kocewiak, K.; Talaga, J.; Postnikova, I. Mechanisms of trapping fine dust in wet dust collecting apparatus. Izv. Vyss. Uchebnykh Zaved. Khimiyai Khimicheskaya Tekhnologiy 2019, 62, 97-101, doi:10.6060/ivkkt.20196209.5926. [CrossRef]

43. Ngo, S.I.; Lim, Y.-I. Multiscale Eulerian CFD of chemical process: A review. ChemEngineering 2020, 4, 23, doi:10.3390/chemengineering4020023. [CrossRef]

44. Jaworski, Z. Computational Fluid Dynamics; Exit: Warsaw, Poland, 2005. (In Polish)

45. Gambit 2.4-Documentation; Fluent Inc.: New York, NY, USA, 2006.

46. Meshing-User's Guide; Ansys Inc.: Canonsburg, PA, USA, 2013.

47. Ansys Fluent 14.0-Theory Guide; Ansys Inc.: Canonsburg, PA, USA, 2011.

48. Ansys Fluent 14.0-User's Guide; Ansys Inc.: Canonsburg, PA, USA, 2011.

49. Pope, S.B. Turbulent Flows; Cambridge University Press: Cambridge, UK, 2000.

50. Wójtowicz, R.; Lipin, A.A.; Talaga, J. On the possibility of using of different turbulence models for modeling flow hydrodynamics and power consumptionin mixing vessels with turbine impellers. Theor. Found. Chem. Eng. 2014, 48, 386-402. [CrossRef]

51. Yakhot, V.; Orszag, S.A. Renormalization group analysis of turbulence. J. Sci. Comput. 1986, 1, 3-51. [CrossRef]

52. Andersson, B.; Andersson, R.; Hakansson, L.; Mortensen, M.; Sudiyo,R.; van Wachem, B. Computational Fluid Dynamics for Engineers; Cambridge University Press: Cambridge, UK, 2012.

53. Fitouri, A.; Khan, M.K.; Bruun, H.H. A multiposition hot-wire technique for the study of swirling flows in vortex chambers. Exp. Therm. Fluid Sci. 1995, 10, 142-151. [CrossRef]

54. Vatistas, G.H.; Kowk, C.K.; Lin, S. The reduction of pressure drop across a vortex chamber. AIAA J. 1984, 23, 974-975. [CrossRef]

55. Flow Field Diagnostics Constant Temperature Anemometry Solutions; Dantec Dynamics Ltd.: Portbury, UK, 2019.

56. Jørgensen, F.E. How to Measure Turbulence with Hot-Wire Anemometers-A Practical Guide; Dantec Dynamics Ltd.: Skovlunde, Denmark, 2002.

57. Hunt, J.C.R.; Wray, A.A.; Moin, P. Eddies, streams and convergence zones in turbulent flow. In Proceedings of the Summer Program 1988 (CTR-S88); Center for Turbulence Research, Stanfod Univesity: Stanford, CA, USA, 1988; pp. 193-208.

58. Brauer, H. Air Protection Engineering; Cracow University of Technology Press: Cracow, Poland, 2010 ; Volume 27.

59. Coker, A.K. Understand cyclone design. Chem. Eng. Progr. 1993, 28, 51-55. 